\title{
Ultrasound-Guided Percutaneous Long Head of the Biceps Tenotomy
}

\author{
Sim Sai Tin, MD • Viroj Wiwanitkit, MD
}

Received: 30 September 2014/Accepted: 6 November 2014/Published online: 3 February 2015

(C) Hospital for Special Surgery 2015

\section{Dear Editor,}

We would like to discuss on the recent publication of "Ultrasound-guided percutaneous long head of the biceps tenotomy [2]." Greditzer et al. reported a case and mentioned for the usefulness of this technique. In fact, the feasibility of this technique has just been reported by Aly in J. Clin. Ultrasound [4]. Aly et al. noted that "the deep to superficial approach using an arthroscopic hook blade resulted in complete transection [4]." However, Lévy et al. reported that this technique was not reliable [4]. According to the report by Lévy et al. [4], "iatrogenic lesions of the cartilage of the humeral head, the supraspinatus tendon and the subscapularis tendon" are the unwanted outcome. In fact, to perform tenotomy of the long head of the biceps tendon, there are other alternatives. The good example is the arthroscopic tenotomy [5]. In addition, the outcome of any manipulation, adding to the surgical technique, also depends on "preoperative condition and coexistent subscapularis tears" [5]. Further comparative study of this new technique versus other alternative is suggested.

\section{Disclosure}

Conflict of Interest: Sim Sai Tin, MD and Viroj Wiwanitkit, MD have declared that they have no conflict of interest.
Human/Animal Rights: This article does not contain any studies with human or animal subjects performed by any of the authors.

Informed Consent: N/A

\section{References}

1. Aly AR, Rajasekaran S, Mohamed A, et al. Feasibility of ultrasound-guided percutaneous tenotomy of the long head of the biceps tendon-A pilot cadaveric study. Journal of Clinical Ultrasound. 2014. doi:10.1002/jcu.22189.

2. Greditzer HG 4th, Kaplan LD, Lesniak BP, et al. Ultrasound-guided percutaneous long head of the biceps tenotomy: a novel technique with case report. HSS Journal. 2014; 10(3): 240-244.

3. Karataglis D, Papadopoulos P, Boutsiadis A, et al. Ultrasound evaluation of the distal migration of the long head of biceps tendon following tenotomy in patients undergoing arthroscopic repair of tears of the rotator cuff. Journal of Bone and Joint Surgery (British). 2012; 94(11): 1534-1539.

4. Lévy B, Ducat A, Gaudin P, et al. Ultrasound-guided percutaneous tenotomy of the long head of the biceps tendon: a non-reliable technique. Knee Surgery, Sports Traumatology, Arthroscopy. 2012; 20(6): 1027-1030.

5. The B, Brutty M, Wang A, et al. Long-term functional results and isokinetic strength evaluation after arthroscopic tenotomy of the long head of biceps tendon. International Journal of Shoulder Surgery. 2014; 8(3): 76-80.
Electronic supplementary material The online version of this article (doi:10.1007/s11420-014-9424-6) contains supplementary material, which is available to authorized users.

S. S. Tin, MD $(\bowtie)$

Medical Center, Shantou, China

e-mail:simsaitin@gmail.com

V. Wiwanitkit, MD

Hainan Medical University, Hainan, China 